\title{
Pengaruh Model Pembelajaran Problem Solving Berbantuan Media Audio Visual terhadap Penguasaan Kompetensi Pengetahuan Matematika
}

\author{
Dewa Ayu Diah Adnyani ${ }^{1 *}$, Ni Nyoman Ganing ${ }^{2}$, I Ketut Adnyana Putra ${ }^{3}$ \\ 1,2,3 Jurusan Pendidikan Guru Sekolah Dasar, Universitas Pendidikan Ganesha, Singaraja, Indonesia
}

\author{
A R T I C LEINFO \\ Article history: \\ Received 2 Desember 2017 \\ Received in revised form \\ 28 Desember 2017 \\ Accepted 19 Januari 2018 \\ Available online 20 \\ Februari 2018 \\ Kata Kunci: \\ problem solving, media \\ audio visual, kompetensi \\ pengetahuan matematika \\ Keywords: \\ Problem Solving, audio- \\ visual media ,knowledge \\ competence of mathematics
}

\begin{abstract}
A B S T R A K
Penelitian ini bertujuan untuk mengetahui perbedaan yang signifikan kompetensi pengetahuan Matematika antara siswa yang dibelajarkan menggunakan model Pembelajaran Problem Solving berbantuan media audio visual dan siswa yang dibelajarkan menggunakan model pembelajaran konvensional pada siswa kelas $\mathrm{V}$ SD Gugus Srikandi Tahun Ajaran 2016/2017. Jenis penelitian yang digunakan adalah eksperimen semu, dengan desain penelitian "Nonequivalent Control Group Design". Populasi penelitian ini adalah seluruh siswa kelas V SD Gugus Srikandi dengan jumlah 396 siswa. Sampel diambil dengan teknik Random Sampling. Sampel dalam penelitian ini yaitu siswa kelas VB SD Negeri 1 Sumerta sebagai kelas eksperimen dan siswa kelas V SD Negeri 2 Sumerta sebagai kelas kontrol dengan jumlah masing-masing kelompok sebanyak 34 siswa pada kelompok ekperimen dan 24 orang siswa pada kelompok kontrol. Data dikumpulkan dengan instrumen berupa tes pilihan ganda. Data dianalisis dengan menggunakan uji-t. Hasil analisis menunjukkan bahwa terdapat perbedaan yang signifikan kompetensi pengetahuan
\end{abstract} Matematika siswa yang dibelajarkan dengan Model Pembelajaran Problem Solving berbantuan media audio visual dengan siswa yang mendapatkan pembelajaran konvensional $\left(t_{\text {hit }}=7,09>t_{\text {tabel }}=2,003\right)$ dengan $\mathrm{dk}=56$ dan taraf signifikansi $5 \%$. Dengan demikian dapat disimpulkan bahwa model Pembelajaran Problem Solving bebantuan media audio visual berpengaruh signifikan terhadap kompetensi pengetahuan Matematika siswa kelas V.

\section{A B S T R A C T}

This study aims to determine the significant differences in the competence of students' knowledge that is learned through the model of Problem Solving learning aided by audio visual media and students who are taught through conventional learning model on V grade students of SD Srikandi School of the Year 2016/2017. This type of research is a quasi experiment. The design of this research using "Non equivalent Control Group Design". The population of this study is all students of grade V SD Sugandi Cluster with a population of 396 students. Samples were taken by Random Sampling technique. The sample in this research is the students of VB SD Negeri 1 Sumerta class as the experimental class and the students of grade V SDNegeri 2 Sumerta as the control class with the number of each group of 34 students in the experimental group and 24 students in the control group. Data were collected with instruments of multiple choice tests. Mathematical knowledge competence test is given at post test in writing. Furthermore, the data were analyzed by using t-test. The results showed that based on t-test analysis can be seen there is a significant difference in the knowledge competence of Mathematics students who are taught by Problem Solving Model with audio-visual media supported by students who get conventional learning (thit $=7.09>$ ttable $=2,003$ ) with $\mathrm{dk}=56$ and a significance level of $5 \%$. Thus it can be concluded that the model of Problem Solving Learning buhantuan audiovisual media significant effect on the competence of knowledge Mathematics students of class V.

Copyright (C) Universitas Pendidikan Ganesha. All rights reserved.

\footnotetext{
${ }^{1}$ Corresponding author.

E-mail addresses: diahadnyani69@gmail.com (Dewa Ayu Diah Adnyani)
} 


\section{Pendahuluan}

Sistem pendidikan di Indone-sia ternyata telah mengalami banyak perubahan. Perubahanperubahan itu terjadi karena telah dilakukan berbagai usaha pembaharuan dalam pendidikan. Sejalan dengan kemajuan tersebut, ma-ka dewasa ini pendidikan di sekolah-sekolah telah menunjukkan perkembangan yang sangat pesat. Perkem-bangan itu terjadi karena terdorong ada-nya pembaharuan, sehingga di dalam pembelajaran banyak ditemukan meto-de dan peralatan baru yang dapat mem-berikan semangat belajar bagi siswa. Bahkan secara keseluruhan dapat dika-takan bahwa pembaharuan dalam sis-tem pendidikan yang mencakup seluruh komponen yang ada.

Untuk itu diperlukan suatu upaya dalam rangka meningkatkan mutu pembelajaran salah satunya ada-lah dengan memilih pendekatan atau cara dalam menyampaikan materi pela-jaran agar diperoleh peningkatan hasil belajar siswa. Misalnya dengan mem-bimbing siswa untuk bersama-sama ter-libat aktif dalam proses pembelajaran dan mampu membantu siswa berkem-bang sesuai dengan taraf intelektualnya akan lebih menguatkan pemahaman siswa terhadap konsep-konsep yang diajarkan.

Kurikulum Tingkat Satuan Pendidikan (KTSP) yang sekarang telah disempurnakan menjadi kurikulum 2013 , penyempurnaan kurikulum tidak seke-dar untuk memperbaiki kesalahan atau menyempurnakan kekurangan, tetapi juga mencoba hal-hal baru, yaitu hal-hal yang secara konseptual, prosedural, dan kualitatif berbeda dengan yang biasa digunakan.Inovasi tidak selalu berkenaan dengan sesuatu yang asing. Dalam kurikulum 2013 proses pem-belajaran dipayungi oleh sebuah tema yang mengaitkan beberapa mata pelajaran sehingga pemisahan antar mata pelajaran tidak terlalu jelas terlihat. Kurikulum 2013 pembelajaran dilaksanakan memalui Pendekatan Saintifik untuk memberikan pemahaman kepada siswa dalam mengenal, memahami berbagai materi mengguna-kan pendekatan ilmiah, bahwa informasi bisa berasal dari mana saja, kapan saja, tigak tergantung pada informasi searah dari guru. Berdasarkan uraian tersebut salah satu model atau metode pembelajaran yang sesuai dengan hal-hal tersebut adalah model atau metode pembelajaran berbasis Masalah (prob-lem base learning).

Berdasarkan hasil wawancara di 8 SD di Gugus Srikandi pada tanggal 26 Desember 2016 diditemukan skor nilai penguasaan kompetensi penge-tahuan Matematika masih rendah. Ba-nyaknya siswa beranggapan bahwa pelajaran Matematika tersebut sangat sulit, banyak menghafal rumus-rumus dan menghitung bilangan diluar kemam-puan siswa. Itu menyebabkan rendah-nya penguasaan kompetensi penge-tahuan Matematika.

Dari permasalahan tersebut perlu solusi perbaikan penguasaan kompetensi pengetahuan Matematika siswa sehingga dapat menuntaskan permasalahan penguasaan kompetensi pengetahuan Matematika siswa menjadi siswa yang percaya diri, disiplin dan mampu bekerja sama dengan teman sebayanya. Menurut Killen (1998), pemecahan masalah sebagai strategi pembelajaran adalah suatu teknik di-mana masalah digunakan secara lang-sung sebagai alat untuk membantu siswa memahami materi pelajaran yang sedang mereka pelajari. Model pembelajaran problem solving merupa-kan sebuah model pemecahan masalah yang memancing cara berpikir siswa dalam memecahkan masalah yang diberikan. Model ini juga akan membuat siswa lebih aktif selama proses pem-belajaran. Karena siswa yang dituntut lebih aktif (student center) selama pro-ses pembelajaran. Model ini cocok di-terapkan untuk pelajaran Matematika, karena dalam pelajaran Matematika perlu pemahaman yang kuat agar pem-belajara mampun dikuasai oleh siswa. Banyak asumsi bahwa pelajaran Mate-matika merupakan pelajaran yag sulit untuk dipahami, dan bayak rumus yag harus dihafalkan oleh siswa. Model Pembelajaran problem solving akan membuat pelajaran Matematika lebih menarik dan bermakna. Karena siswa diberikan kesempatan untuk mem-bangun pengetahuannya sendiri melalui cara memecahkan masalah yang di-temukan oleh siswa. Sehingga penge-tahuan siswa tidak hanya bersifat se-mentara. "media audio visual adalah segala sesuatu yang dapat menyam-paikan atau menyalurkan pesan dari suatu sumber secara terencana, se-hingga terjadi lingkungan belajar yang kondusif dimana penerimanya dapat melakukan proses belajar secara efisien dan efktif" (Asyhar, 2012:8). Dengan bantuan media audio visual akan mem-bantu dalam penyampaian materi secara lebih menarik. Siswa akan lebih tertarik dalam menyimak proses pembelajaran. Sehingga proses pembela-jaran akan lebih menyenangkan, me-narik, siswapun akan lebih aktif selama proses pembelajaran

Dari uraian tersebut maka dilakukan suatu penelitian yang berjudul "Pengaruh Model Pembelajaran Pro-blem Solving Berbantuan Media Audio Visual Terhadap Penguasaan Kom-petensi Pengetahuan Matematika Siswa Kelas V SD Gugus Srikandi Tahun Ajaran 2016/2017".

\section{Metode}

Penelitian ini dilaksanakan di SD Gugus Srikandi Kecamatan Denpasar Timur, Kabupaten Denpasar. Pemilihan SD ini sebagai tempat penelitian dengan alasan di SD Gugus Srikandi sudah menerapkan 
kurikulum 2013 dan belum pernah diadakan penelitian dengan menerapkan model pembelajaran Problem Solving berbantuan media audio visual. Penelitian ini dilak-sanakan di SD Negeri 1 Sumerta dan SD Negeri 2 Sumerta yang dimulai dari tanggal 17 April 2017.

Penelitian ini akan dilaksanakan pada semester 2 tahun ajaran 2016/2017 di kelas V SD Gugus Srikandi. Jenis penelitian yang dilakukan dalam penelitian ini adalah penelitian kuantitatif dengan desain eksperi-mental. Bentuk desain eksperimen semu yang digunakan dalam penelitian ini adalah Nonequivalent Control Group Design. Pada penelitian bentuk ini biasanya dipakai pada eksperimen yang menggunakan kelas yang sudah terbentuk dan tidak dilakukannya pe-ngacakan individu. Jadi, pada rancangan ini tidak dibentuk kelas baru dalam penelitian.

Pada desain ini, baik kelompok eksperimental maupun kelompok kontrol dibandingkan. Penyetaraan dilakukan pada kelompok kontrol dan kelompok eks-perimen. Setelah itu peneliti memberikan perlakuan, yaitu dengan memberikan model pembelajaran problem solving berbantuan media audio visual kepada kelompok eksperimen dan pembelajaran konven-sional dilaksanakan seperti biasa pada kelompok kontrol. Kemudian setelah di-berikan perlakuan, dilakukan posttest untuk mengetahui penguasaan kompetensi pe-ngetahuan. Penyetaraan dilakukan untuk memastikan kemampuan awal dari ke-lompok eksperimen dan kelompok kontrol sama, agar hasil akhir penelitian tidak dipengaruhi oleh kemampuan yang tidak setara, namun karena perlakuan yang diberikan.

Rancangan penelitian berhubungan dengan suatu variabel penelitian dalam perlakuan yang diberikan. Variabel penelitian dalam perlakuan yang diberikan melibatkan variabel. Variabel bebas sering juga disebut variabel independen atau prediktor. Variabel bebas dalam penelitian ini adalah model pembelajaran Problem Solving berbantuan media audio visual yang digunakan pada kelas eksperimen dan pembelajaran konvensional pada kelas kontrol. Variabel terikat dalam penelitian ini adalah penguasaan kompetensi penge-tahuan Matematika siswa kelas V SD.

Populasi Populasi dari penelitian ini adalah seluruh siswa kelas V (lima) SD Gugus Srikandi tahun pelajaran 2016/2017. Jumlah populasi penelitian ini terdiri dari 8 sekolah dasar, dengan 396 orang siswa kelass V SD, dengan rincian pada tabel berikut.

Tabel 1. Data Siswa Kelas V SD Gugus Srikandi

\begin{tabular}{llll}
\hline No & Nama Sekolah & Kelas & Jumlah Siswa \\
\hline & SD N 1 Sumerta & $\mathrm{V}$ & 84 \\
\hline 1 & SD N 2 Sumerta & $\mathrm{V}$ & 26 \\
\hline 2 & $\mathrm{~V}$ & 57 \\
\hline 3 & SD N 5 Sumerta & $\mathrm{V}$ & 38 \\
\hline 4 & SD N 8 Sumerta & $\mathrm{V}$ & 29 \\
\hline 5 & SD N 10 Sumerta & $\mathrm{V}$ & 190 \\
\hline 6 & SD Cipta Dharma & $\mathrm{V}$ & 108 \\
\hline 7 & SD It Al Bana & $\mathrm{V}$ & 69 \\
\hline 8 & SD N 13 Kesiman & & 396 \\
\hline \multicolumn{2}{l}{ Total } & & \\
\hline
\end{tabular}

Teknik pengambilan sampel pada penelitian ini adalah Random Sampling yang dirandom kelasnya, sehingga setiap kelas mendapatkan peluang yang sama untuk menjadi sampel penelitian. Pe-milihan sampel penelitian ini tidak dila-kukannya pengacakan individu melainkan hanya pengacakan kelas. Karena tidak bisa mengubah kelas yang telah ter-bentuk sebelumnya. Kelas dipilih se-bagaimana telah terbentuk tanpa campur tangan peneliti dan tidak dilakukannya pengacakan individu, kemungkinan pengaruh-pengaruh dari keadaan siswa me-ngetahui dirinya dilibatkan dalam eks-perimen dapat dikurangi sehingga pe-nelitian ini benar-benar menggam-barkan pengaruh perlakuan yang diberikan.

Cara yang digunakan adalah dengan cara pengundian. Cara undian dilakukan dengan menulis semua nama SD populasi pada masing-masing kertas, kemudian kertas digulung. Masukkan gulungan kertas ke dalam kotak dan di-kocok. Ambil dua gulungan kertas. Nama-nama SD pada kedua gulungan kertas tersebut merupakan sampel penelitian. Apabila dalam SD terpilih terdapat kelas yang pararel dilakukan lagi pengundian untuk menentukan kelas yang akan di-gunakan sebagai sampel.

Sampel yang diperoleh dari hasil random adalah kelas VB SD Negeri 1 Sumerta berjumlah 34 siswa dan kelas V SD Negeri 2 Sumerta berjumlah 24 siswa. Untuk menyatakan bahwa kedua kelas tersebut setara dilakukan pengujian ke-setaraan kelas dengan menggunakan uji-t, sebelum menggunakan uji-t terlebih da-hulu akan dilakukan uji normalitas dan ho-mogenitas. 
Berdasarkan analisis uji norma-litas data, dibawah ini disajikan reka-pitulasi hasil uji normalitas untuk kelom-pok eksperimen dan kelompok kontrol de-ngan menggunakan rumus Chi-Kuadrat dipaparkan pada tabel berikut.

Tabel 2. Rekapitulasi Data Uji Normalitas Nilai Tema Sebelumnya

\begin{tabular}{lllll}
\hline No. & Sampel Penelitian & $X_{\text {hitung }}$ & $X_{\text {tabel }}$ & Keterangan \\
\hline 1. & SD Negeri 1 Sumerta & 2,38 & 11,070 & Data Berdistribusi Normal \\
\hline 2. & SD Negeri 2 Sumera & 1,37 & 11,070 & Data Berdistribusi Normal \\
\hline
\end{tabular}

Berdasarkan perhitungan hasil uji normalitas nilai pada tema sebelumnya ke-lompok eksperimen $\mathrm{X}^{2}{ }_{\text {hitung }}=2,38$ dan $X^{2}$ tabel $=11,070$, karena $X^{2}$ hitung $<X_{\text {tabel }}(2,38<11,070)$ maka data berdistribusi normal. Be-rdasarkan perhitungan hasil uji normalitas nilai pada tema sebelumnya kelompok kontrol $X^{2}$ hitung $=$ 1,37dan $X_{\text {tabel }}=11,070$, karena $X^{2}{ }_{\text {hitung }}<X^{2}$ tabel $(1,37<11,070)$ maka data berdistribusi normal.

Berdasarkan analisis uji homo-genitas, di bawah ini disajikan rekapitulasi hasil uji homogenitas untuk kelompok eksperimen dan kelompok kontrol dengan menggunakan uji F. Rekapitulasi uji homogenitas dipaparkan pada tabel berikut.

Tabel 3. Rekapitulasi Data Uji Homogenitas Nilai Tema Sebelumnya

\begin{tabular}{lllllll}
\hline No. & Sampel Penelitian & $\mathrm{S}^{2}$ & $\mathrm{Dk}$ & $\mathrm{F}_{\text {hitung }}$ & $\mathrm{F}_{\text {tabel }}$ & \multirow{2}{*}{ Keterangan } \\
\cline { 1 - 5 } 1. & SD Negeri 1 Sumerta & 7,65 & 33 & 0,96 & 1,96 & \multirow{2}{*}{ Homogen } \\
\hline 2. & SD Negeri 2 Sumerta & 7,65 & 23 & & & \\
\hline
\end{tabular}

Berdasarkan uji homogenitas $\mathrm{F}_{\text {hitung }}=0,96$ dan $\mathrm{F}_{\text {tabel }}=1,96$, karena harga $\mathrm{F}_{\text {hitung }}<\mathrm{F}_{\text {tabel }}$ maka data homogen. Karena data nilai pada tema sebelumnya untuk kelompok eksperimen dan kontrol berdistribusi normal dan homogen dilanjutkan de-ngan melakukan uji kesetaraan dengan uji-t. Kesetaraan sampel diuji dengan rumus uji-t yakni bentuk polled varian karena jum-lah $\mathrm{n}_{1} \neq \mathrm{n}_{2}$. Hasil $t_{\text {hitung }}$ diperoleh 0,01 pada taraf signifikansi $5 \%$ dengan $\mathrm{dk}=34+24-2=56$, diperoleh $t_{\text {tabel }}$ sebesar 2,003 . Berdasarkan hasil analisis berarti $t_{\text {hitung }}=0,01<t_{\text {tabel }}=2,003$ yang menyatakan bahwa kedua kelompok sampel setara.

Tes penguasaan kompetensi penge-tahuan Matematika yang digunakan dalam penelitian ini disusun oleh peneliti sendiri. Sebelum memberikan tes tersebut kepada siswa dilakukan pengujian untuk menguji kelayakan instrumen. Tes yang baik adalah tes yang memenuhi dua syarat yaitu ketepatan (validitas) dan keajegan atau ketetapan (reliabilitas). Tes yang akan di-gunakan untuk mengukur penguasaan kompetensi pengetahuan berupa tes ob-jektif dalam bentuk pilihan ganda biasa dilakukan pengujian instrumen yaitu uji validitas, reliabilitas, daya beda dan indeks kesukaran.

Tes pilihan ganda biasa ini meliputi 4 pilihan jawaban (a, b, c atau d) dengan jumlah pertanyaan yaitu 40 butir soal. Setiap item diberikan skor 1 bila siswa menjawab dengan benar (jawaban dise-suaikan dengan kunci jawaban) dan skor 0 bila siswa menjawab salah. Skor setiap jawaban benar dijumlahkan dan jumlah tersebut menjadi skor variabel penguasaan kompetensi pengetahuan Ma-tematika yang bergerak dari kisaran 0 - 40. 0 merupakan skor minimal dan 40 merupakan skor maksimal tes penguasaan kompetensi pengetahuan Matematika. Sebanyak 40 butir soal yang diberikan kepada siswa kelas V SD memiliki tujuan validasi butir tes

Data yang diperlukan dalam pene-litian ini adalah data kompetensi penge-tahuan Matematika. Untuk memperoleh da-ta yang baik diperlukan uji validitas terha-dap suatu instrumen yang digunakan untuk mengumpulkan data. Instrumen penelitian yang dihasilkan dalam penelitian ini uji validitas tes, reliabilitas tes, daya beda tes dan indeks kesukaran.

Berdasarkan uji validias, daya beda, tingkat kesukaran dan reliabilitas diperoleh 30 butir soal yang akan digunakan untuk mengukur penguasaan kompetensi penge-tahuan Matematika kelas V. Hasil analisis uji reliabilitas 30 butir tes diperoleh $r_{11}$ yaitu 0,92 sehingga dari perhitungan dapat dinyatakan bahwa reliabilitas instrumennya sangat tinggi. Daya beda diperoleh 17 butir tes dengan kriteria baik sekali, 9 butir tes dengan kriteria baik, 4 butir tes dengan kriteria cukup dan tidak ada butir tes dengan kriteria jelek. Berdasarkan perhi-tungan tingkat kesukaran hasil analisis memperoleh 7 butir soal dengan kriteria ti-ngkat kesu-karan mudah, 16 butir soal de-ngan kriteria tingkat kesukaran sedang, dan 7 butir soal dengan kriteria tingkat kesu-karan sukar. 


\section{Hasil dan Pembahasan}

Data Hasil analisis statistik deskriptif penguasaan kompetensi pengetahuan Ma-tematika siswa baik kelas eksperimen maupun kelas kontrol dapat dilihat pada tabel 4.

Tabel 4. Deskripsi Penguasaan Kompetensi Pengetahuan Matematika Kelas Eksperimen dan Kelas Kontrol

\begin{tabular}{lll}
\hline Statistik Deskriptif & Kelas Eksperimen & Kelas Kontrol \\
\hline $\mathrm{n}$ & 34 & 24 \\
\hline Rata-rata & 78,71 & 73,47 \\
\hline Nilai Tertinggi & 87 & 83 \\
\hline Nilai Terendah & 63 & 63 \\
\hline Standar Deviasi & 6,41 & 5,85 \\
\hline Varian & 41,07 & 34,29 \\
\hline
\end{tabular}

Berdasarkan hasil analisis data diperoleh nilai rata-rata kelas eksperimen yaitu 78,71 dan kelas kontrol yaitu 73,47 yang dikonversikan ke dalam PAP skala lima termasuk dalam kategori sedang. Data yang diperoleh kemudian dianalisis dengan uji-t yang terlebih dahulu diuji prasyarat yakni uji normalitas dan homogenitas.

Hasil uji normalitas kelas eksperimen menunjukkan bahwa Berdasarkan nilai $X^{2}$ tabel $=11,07$ dan hasil $X_{\text {hitung }}^{2}=7,57$ sehingga harga $X_{\text {hitung }}^{2}<X_{\text {tabsi }}^{2}$ yang ber-arti penguasaan kompetensi pengetahuan Matematika siswa kelas eksperimen ber-distribusi normal. Hasil uji normalitas kelas kontrol menunjukkan bahwa $X_{\text {tabel }}=11,07$ dan hasil $X_{\text {hitung }}^{2}=5,76$ sehingga harga $X_{\text {hitung }}^{2}<X_{\text {tabsi }}^{2}$ yang berarti penguasaan kompetensi pengetahuan Matematika siswa kelas kontrol berdistribusi normal. Hasil uji homogenitas varian data penguasaan kom-petensi pengetahuan Matematika menun-jukkan bahwa $F_{\text {hitung }}$ $=1,20<F_{\text {tabel }}=1,96$ sehingga harga $F_{\text {hitung }}<F_{\text {tabel. }}$ Ini berarti bahwa varians antara kelompok siswa yang dibelajarkan melalui model pembelajaran Problem Solving berbantuan media audio visual dan kelompok siswa yang dibe-lajarkan melalui pembelajaran konvensional homogen

Setelah uji prasyarat dilakukan, se-lanjutnya dilakukan uji hipotesis dengan rumus uji-t bentuk polled varians dengan kriteria jika harga $t_{\text {hitung }} \leq t_{\text {tabel}}$, maka $H_{o}$ diterima dan $H_{a}$ ditolak, dan jika harga $t_{\text {hitung }}$ $>t_{\text {tabel, }}$ maka $\mathrm{H}_{\mathrm{o}}$ ditolak dan $\mathrm{H}_{\mathrm{a}}$ diterima. Pada taraf signifikansi $5 \%$ dengan $\mathrm{dk}=\mathrm{n}_{1}+\mathrm{n}_{2}-2$. Hipotesis yang diuji dalam penelitian ini adalah tidak terdapat perbedaan yang signifikan penguasaan kompetensi pengetahuan Matematika an-tara siswa kelas V SD N Gugus Srikandi Denpasar Timur yang dibelajarkan dengan model pembelajaran Problem Solving berbantuan media audio visual dan siswa yang dibelajarkan dengan pembelajaran konvensional. Rekapitulasi hasil uji hipote-sis data penguasaan kompetensi pengeta-huan Matematika dapat dilihat pada tabel 5.

Tabel 5. Rekapitulasi Hasil Uji Hipotesis Data Penguasaan Kompetensi Pengetahuan Matematika

\begin{tabular}{lcclllll}
\hline $\begin{array}{l}\text { Sampel } \\
\text { Penelitian }\end{array}$ & $\mathrm{N}$ & $\mathrm{Dk}$ & $\overline{\boldsymbol{X}}$ & $\mathrm{S}^{2}$ & $\mathrm{t}_{\text {hitung }}$ & $\mathrm{t}_{\text {tabel }}$ & Keterangan \\
\hline $\begin{array}{l}\text { Kelas } \\
\text { Ekesperimen }\end{array}$ & 34 & 56 & 78,72 & 41,07 & 7,09 & 2,003 & Ha diterima \\
Kelas Kontrol & 24 & & 73,47 & 34,29 & & & \\
\hline
\end{tabular}

Berdasarkan tabel tersebut diketahui bahwa data penguasaan kompetensi pengetahuan Matematika kelas eksperimen dan kelas kontrol memperoleh $t_{\text {hitung }}=7,09$. Nilai $t_{\text {hitung }}$ tersebut dibandingkan dengan $t_{\text {tabel }}=$ 2,003 . Karena harga $t_{\text {hitung }}>t_{\text {tabel, }}$ maka $H_{a}$ diterima yang berbunyi " terdapat perbedaan yang signifikan kompetensi pengetahuan Mate-matika antara kelompok siswa yang dibela-jarkan menggunakan model Pembelajaran Problem Solving berbantuan media audio visual dan kelompok siswa yang dibela-jarkan menggunakan pembelajaran konven-sional pada siswa kelas V SD Gugus Sri-kandi Kecamatan Denpasar Timur Tahun Ajaran 2016/2017". Hal tersebut menun-jukkan bahwa terdapat perbedaan yang signifikan penguasaan kompetensi penge-tahuan Ma-tematika antara siswa kelas V SD N Gugus Srikandi yang dibelajarkan dengan model pembelajaran Problem Solv-ing berbantuan media audio visual dan siswa yang dibelajarkan dengan pembela-jaran konvensional.

Data yang dianalisis pada penelitian ini adalah data hasil kompetensi pengetahuan Matematika siswa Kelas V tema 9 Lingkungan Sekitar Kita pada kelompok eksperimen dan kelompok kontrol. Data 
hasil penguasaan kompetensi pengetahuan Matematika diperoleh dari ha-sil posttest yang diberikan pada akhir penelitian. Kelompok eksperimen yang di-gunakan dalam penelitian ini yaitu kelas V SD Negeri 1 Sumerta berjumlah 34 siswa, sedangkan kelompok kontrol adalah kelas V SD Negeri 2 Sumerta berjumlah 24 sis-wa. Maka jumlah siswa dalam penelitian ini sebanyak 58 siswa. Instrumen yang digu-nakan untuk mengumpulkan data adalah tes objektif pilihan ganda biasa. Rancangan penelitian yang digunakan dalam penelitian ini adalah rancangan Nonequivalent Control Grup Design dengan menggunakan uji-t sebagai alat untuk menganalisis data.

Kelas V SD Negeri 1 Sumerta ditetapkan sebagai kelompok eksperimen yang diberi perlakuan berupa model pem-belajaran Problem Solving berbantuan media audio visual sebanyak 6 kali per-temuan, kemudian diberikan posttest untuk memperoleh hasil kompetensi pengetahuan Matematika siswa.

Kelas V SD Negeri 2 Sumerta seba-gai kelompok kontrol yang diberi dibela-jarkan menggunakan pembelajaran konven-sional sebanyak 6 kali pertemuan, kemu-dian diberikan posttest untuk memperoleh hasil kompetensi pengetahuan Matematika siswa.

Pada akhir penelitian di kelas eks-perimen dan kelas kontrol diberikan post-test untuk mendapatkan data penguasaan kompetensi pengetahuan Matematika sis-wa. Hasil analisis data dari kelas eks-perimen yang dibelajarkan dengan model pembelajaran Problem Solving berbantuan media audio visual memperoleh nilai rata-rata 78,72 dan kelas kontrol yang dibela-jarkan dengan pembelajaran konvensional memperoleh nilai rata-rata 73,47. Se-lanjutnya data penguasaan kompetensi pengetahuan Matematika diuji menggu-nakan uji-t dan diperoleh $t_{\text {hitung }}=7,09$ seda-ngkan pada taraf signifikansi $5 \%$ dan $\mathrm{dk}=56$ diperoleh nilai $\mathrm{t}_{\text {tabe }}=2,003$ sehingga $t_{\text {hitnung }}=7,09>\mathrm{t}_{\text {tabel }}=2,003$. Dengan demikian $\mathrm{H}_{\mathrm{o}}$ ditolak yang berarti terdapat perbedaan yang signifikan penguasaan kompetensi pengetahuan Matematika an-tara siswa kelas V SD Gugus Srikandi yang dibelajarkan dengan model pembelajaran Problem Solving berbantuan media audio visual dan siswa yang dibelajarkan dengan pembelajaran konvensional. Hal tersebut juga didukung dengan adanya perbedaan nilai rata-rata penguasaan kompetensi pengetahuan Matematika antara kelas eksperimen yaitu $\bar{X}=78,72$ dan $\bar{X}=73,47$ pada kelas kontrol.

Penguasaan kompetensi penge-tahuan Matematika siswa pada kelas eksperimen lebih baik apabila dibandingan dengan penguasaan kompetensi pengeta-huan Matematika siswa pada kelas kontrol. Hal ini disebabkan oleh model pembe-lajaran Problem Solving berbantuan media audio visual merupakan pembelajaran yang menuntut keaktifan dan rasa ingin tahu siswa dalam memecahkan masalah yang diberikan. Suatu inovasi pembelajaran yang mendorong siswa aktif dan bertanggung jawab hasil dari pemecahan masalah yang ditemukan sendiri oleh siswa dengan mem-anfaatkan media audio visual dalam proses untuk menunjang kegiatan pembelajaran agar berjalan lebih menarik. Selama kegi-atan pembelajaran siswa diajak untuk mem-bangun pengetahuannya sendiri melalui apa yang telah ditemukan oleh siswa. Penggunaan model pembelajaran Problem Solving mengarahkan siswa untuk aktif, mampu membangun pengetahuannya sen-diri dengan cara yang mudah dimengerti dan dipahami oleh siswa. Berbantuan media audio visual yang melibatkan indera penglihatan dan pendengaran siswa akan lebih mudah memahami suatu konsep yang abstrak menjadi lebih konkret dan me-nambah daya tahan ingatan tentang objek belajar yang dipelajari. Berbeda pada ke-lompok kontrol, kegiatan pembelajaran konvensional yang hanya menggunkaan pen-dekatan saintifik berjalan kurang optimal. Hal ini disebabkan siswa yang kurang mampu mengaitkan antar materi pada mu-atan materi Matematika yang menurut para siswa sukar untuk dipahami. Pembelajaran menggunakan model pembelajaran Prob-lem Solving berbantuan media audio visual pada muatan materi Matematika membe-rikan kesempatan yang lebih luas kepada siswa untuk mengonstruksikan pengeta-huannya melalui pemahamannya sendiri tentunya menyenangkan bagi siswa pada setiap langkah pembelajarannya.

Penelitian ini diperkuat dengan hasil penelitian Ign. I Wayan Suwatra (2014) yang hasil penelitiannya menunjukkan bah-wa terdapat perbedaan yang signifikan ke-mampuan berpikir kritis siswa pada mata pelajaran IPS yang mendapatkan pembela-jaran dengan modeln Creative Problem Solving (CPS) dengan siswa yang men-dapat pembelajaran konvensional. Diper-kuat juga dengan jurnal Puspitasari(2014) yang hasilnya juga menunjukan terdapat perbedaan yang signifikan prestasi belajar IPS siswa yang mendapat pembelajaran Problem Based Instruction berbantuan media audio visual dengan siswa yang mendapat pembelajaran konvensional.

Dengan demikian, pembelajaran menggunakan model pembelajaran Prob-lem Solving berbantuan media audio visual pada penelitian ini memiliki keunggulan, ya-itu pembelajaran yang membangun penge-tahuannya sendiri, siswa lebih aktif dalam belajar dan dapat memberikan keber-maknaan dalam proses pembelajaran. Model pembelajaran ini menekankan pada proses pembelajaran yang memberikan kesempatan kepada siswa untuk menda-patkan pemahaman secara langsung dan bermakna dalam mengembangkan pola berpikirnya (penalarannya). Selain itu, sis-tem pembelajaran ini membantu siswa me-mecahkan masalah melalui pemaha-mannya sendiri. 


\section{Simpulan dan Saran}

Berdasarkan hasil penelitian dan pemba-hasan, dapat disimpulkan sebagai berikut Berdasarkan hasil penelitian dan pemba-hasan yang telah dilaksanakan maka dapat disimpulkan sebagai berikut.1) Kompetensi pengetahuan Matematika siswa yang dibe-lajarkan melalui model pembela-jaran Prob-lem Solving berbantuan media audio visual pada siswa kelompok ekspe-rimen sebesar 78,71 dengan nilai tertinggi yang diperoleh siswa adalah 87 dan nilai terendah 63, se-hingga kompetensi pengetahuan matema-tika kelompok eksperimen berada pada kategori sedang. 2) Kompetensi pengeta-huan Matematika siswa yang dibalajarkan melalui pembelajaran konvensional pada siswa kelompok kontrol sebesar 73,47 dengan nilai tertinggi yang diperoleh siswa adalah 83 dan nilai terendah 63, sehingga kompetensi pengetahuan matematika ke-lompok Kontrol berada pada kategori seda-ng. 3)Rerata kompetensi pengetahuan Ma-tematika yang diperoleh siswa yang dibela-jarkan melalui model pembelajaran Problem Solving berbantuan media audio visual le-bih tinggi dari siswa ang dibelajarkan mela-lui pembelajaran konvensional $(78,72>73,47)$. Berdasarkan hasil analisis dengan menggunakan uji-t dengan $\mathrm{dk}=56$ pada taraf signifikansi $5 \%$ diperoleh $t_{\text {hitung }}=7,09>t_{\text {tabel }}=2,003$ ini berarti bahwa terdapat perbedaan yang signifikan kompetensi pe-ngetahuan Matematika antara kelompok siswa yang dibelajarkan menggunakan mo-del pembelajaran Problem Solving berban-tuan media audio visual dan kelompok siswa yang dibelajarkan menggunakan pembelajaran konvensional pada siswa ke-las V SD Gugus Srikandi Tahun Ajaran 2016 /2017 pada tema 9 (Lingkungan Sehat Kita). Jadi dapat disimpulkan bahwa terdapat pengaruh model pembelajaran Problem Solving berbantuan media audio visual terhadap kompetensi pengetahuan Matematika siswa kelas IV SD Gugus Srikandi Tahun Ajaran 2016/2017.

Berdasarkan hasil penelitian, pem-bahasan dan simpulan, maka dapat di-ajukan saran kepada beberapa pihak se-bagai berikut. 1) Siswa hendaknya dalam proses pembelajaran lebihh antusias dan bersemangat mengikuti pembelajaran, se-hingga kompetensi pengetahuan dapat mencapai KKM serta ilmu yang diperoleh dapat bermanfaat dalam kehidupan sehari-hari. 2) Guru hendaknya bisa menjadikan penelitian ini sebagai acuan untuk me-ningkatkan keterampilan dalam merancang pembelajaran dengan tujuan memperoleh hasil belajar yang optimal. Khusunya guru yang mengajar di kelas $\mathrm{V}$ yang menggunakan tematik disarankan untuk me-ngembangkan inovasi pembelajaran de-ngan menerapkan strategi, pendekatan, model, dan metode yang mampu meng-optimalkan hasil belajar siswa. Dengan pendekatan saintifik menggunakan perta-nyaan jawaban tertunda menjadi salah satu pendekatan yang dikombinasikan dengan karakteristik pertanyaan guru yang dapat diterapkan dalam proses pembelajaran. 3) Disarankan kepada kepala sekolah hen-daknya menyediakan sarana khususnya media pembelajaran secara maksimal un-tuk menunjang proses pembelajaran se-hingga kualitas pembelajaran di SD lebih optimal, siswa semakin semangat belajar dan hasil kompetensi pengetahuan siswa meningkat serta mutu sekolah meni-ngkat..4) Bagi peneliti lain, hasil ini dapat di-jadikan kajian dalam mengembangkan pe-nelitian selanjutnya

\section{Daftar Rujukan}

Agung, A.A. Gede. 2016. Statistika Dasar untuk Pendidikan. Singaraja:FIP Undiksha

Asyhar, Rayanda. 2012. Kreatif Mengembangkan Media Pembelajaran. Jakarta: Referensi Jakarta

Puspitasari, Luh Dewi. 2014.Pengaruh Model Pembelajaran Problem Based Instruction Berbantuan Media Audio Visual Terhadap Hasil Belajar IPS Siswa Kelas V Gugus Srikandi Denpasar. Skripsi (tidak diterbitkan).Jurusan Pendidikan Guru Sekolah Dasar FIP Undiksha.

Setyosari, Punaji. 2015. Metode Penelitian Pendidikan dan Pengembangan. Jakarta : Prenadamedia Group.

Suwatra, Ign. I Wayan. 2014. Pengaruh Model Creative Problem Solving (CPS) Terhadap Kemampuan Berpikir Kritis Siswa Pada Mata Pelajaran IPA Siswa Kelas V SD. Penelitiam. Jurusan Pendidikan Guru Sekolah Dasar FIP Undiksha 